\title{
Sulfonylureas as treatment choice in Diabetes Mellitus : Where are we now?
}

\author{
Manta A and Peppa M* \\ Endocrine Unit, 2nd Department of Internal Medicine Propaedeutic, Research Institute and Diabetes Centre, National and Kapodistrian University of Athens, \\ Attikon University Hospital, Athens, Greece
}

Sulfonylureas (SUs) constitute a hallmark in the treatment of Diabetes Mellitus Type 2 (DM2) and have remained the main pharmacological approach for many decades. Tolbutamide and the rest of the first-generation SUs were originated in Germany in the 1950s, while the second-generation agents such as glyburide and glipizide were released in the United States in 1984 [1]. Glimepiride, a thirdgeneration SU, became available in the United States in 1995 [2]. In 1997, SUs was the most prescribed class of oral antidiabetic agents, corresponding to over $60 \%$ of all treatment visits [3].

SUs are characterized as insulin secretagogue agents, as they stimulate pancreatic $\beta$-cells to secrete insulin. They bind to the SUR1, a subunit of the potassium ATP-dependent channel on the plasma membrane of $\beta$-cells. SUs binding leads to closing of the channel and subsequent membrane depolarization, which causes the opening of voltage-dependent $\mathrm{L}$-type $\mathrm{C}$ calcium channels. The calcium influx that occurs results in an increase in intracellular calcium, which triggers the exocytosis of insulin granules [4].

Since SUs have been used for more than 60 years, clinicians around the world have extensive experience with them. SUs are known to be quite effective in glycemic control, with a significant reduction in HbAlc. A meta-analysis that compared the oral antidiabetic medications, concerning their effectiveness, reported reduction in HbA1c of $1.25 \%$ with SUs compared to placebo and mentioned that SUs had the greatest effect comparing to the rest of the antidiabetic agents [5]. Other studies report an even greater reduction that reaches $1.6 \%$ [6]. However, according to a different study, SUs seem to have almost the same effect in HbAlc as Thiazolinediones (TZDs) and Dipeptidyl peptidase-4 (DPP4) inhibitors [7]. According to the UKPDS and ADVANCE studies, treatment with SUs demonstrated reduction in microvascular but not macrovascular complications $[8,9]$.

Accumulating data from different studies indicate that SUs improve outcomes in patients presenting with ischemic stroke, by decreasing hemorrhagic transformation and relieving cerebral edema. According to a retrospective study, SUs use in diabetic patients who present with stroke leads to decreased intracerebral hemorrhage and perihematomal edema, while declining inpatient mortality [10].

It should be pointed out that SUs have remarkably lower cost than any of the other antidiabetic agents. In a reality where more and more people are affected by DM2 and medical expenses are a major issue, it is reasonable to try and include inexpensive medications in the daily practice [11].

However, despite the marked effectiveness and the low cost, SUs have a lower priority in the treatment algorithm and their use has been continuously declining, accounting for only about $20 \%$ of diabetes treatment visits in 2012 [3]. This decline is partially due to the fact that newer agents are being approved and used in the daily practice. A systematic review published in March 2019 compares the cost-effectiveness of SUs and the newer antidiabetic medications and concludes that GLP-1 receptor agonists, DPP-4 inhibitors and SGLT2 inhibitors are more cost-effective options for combination therapy with metformin than SUs, TZDs and basal insulin [12].

Also, in the past several years, SUs are known to have several disadvantages that need to be taken into account. Hypoglycemia caused by SUs is one crucial clinical matter and results from their ability to urge insulin secretion even when the blood glucose concentration is low [13]. It has been described in $20-40 \%$ of patients treated with SUs, while severe hypoglycemia occurs in $1-7 \%$ of patients [14]. In a recent Greek retrospective study, the prevalence of SUs-induced hypoglycemia and its consequences appeared to be even higher, occurring in $41.6 \%$ of patients, while $9.1 \%$ reported severe or very severe hypoglycemic episodes [15]. The incidence of hypoglycemia fluctuates, depending on the particular sulfonylurea (SU) agent, the age, the duration of diabetes and the comorbidity. The use of long-acting agents such as chlorpropamide and glyburide is more prone to cause hypoglycemia [16] and should not be considered as appropriate option in older patients [17]. Glyburide specifically is associated with twice as many episodes of hypoglycemia as other SUs [18].

As long as the rest of the oral antidiabetic agents are concerned, SUs clearly increase the risk for hypoglycemic episodes. Compared to metformin as monotherapy, they have a greater than 4 times higher risk and, when added to metformin, they have a 6 times higher risk compared to other agents $[18,19]$. The episodes of severe hypoglycemia may be fewer than those occurring because of insulin [20,21], however they are likely to be more prolonged and associated with greater mortality [16]. Several studies report that SUs are to blame only for mild hypoglycemic episodes and not for severe ones, that is the ones that need medical intervention [6]. That may be true, however both severe and mild hypoglycemia correlate with lower quality of life and considerable long-term consequences [15,22].

${ }^{\star}$ Correspondence to: Melpomeni Peppa, Associate Professor of Endocrinology, Director of Endocrine and Bone Metabolic Disorders Unit, 2nd Department of Internal Medicine Propaedeutic, Research Institute and Diabetes Center, National and Kapodistrian Univeristy of Athens, Haidari 12462, Greece, Tel: 00302105832550, 6946353972,E-mail: moly6592@yahoo.com, molypepa@otenet.gr

Received: March 21, 2019; Accepted: April 01, 2019; Published: April 04, 2019 
Weight gain is another common adverse effect of the treatment with SUs. Patients tend to gain 1-4 kg usually within 1 year, probably because of the anabolic effect of the increased insulin levels [14]. Apart from SUs, insulin and TZDs are also associated with weight gain in contrast to newer antidiabetic agents such as glucagon like peptides 1 (GLP-1) agonists and DPP-4 inhibitors, which seem to facilitate weight loss $[19,23]$.

It is well known that weight loss improves glycemic control, leads to using fewer medications and helps manage the rest of the cardiovascular risk factors. It should be encouraged in all patients with DM type 2, initially through lifestyle changes. However, some authors consider the weight gain because of SUs to be only moderate and varying depending on the agent used and believe that it could be controlled quite easily [16].

Another downside concerning the use of SUs is the fact that they do not have a lasting effect in lowering glucose levels [20]. This inability to maintain a steady glycemic control is probably the consequence of a loss in pancreatic $\beta$-cell function. The ADOPT trial, which was a multicenter, double-blind clinical trial, was designed to evaluate and compare the glycemic control in patients with DM2 receiving monotherapy with a TZD, metformin and a SU. According to the trial, despite the fact that the SU had the greatest effect in decreasing HbAlc within the first 6 months, there was a progressive loss of glycemic control. After 4 years, only $26 \%$ in the group treated with the SU had a $\mathrm{HbA} 1 \mathrm{c}$ of less than $7 \%$. The level of $\beta$-cell function also declined after the first 6 months, with the greatest annual rate of decline in the group of SUs [24]. The loss of $\beta$-cell function is crucial in DM2, as it expedites the time to requiring additional treatment and, eventually, insulin. It is regular tactic the effort to preserve as much $\beta$-cell function as possible, in order to elongate this period. In addition, the ADOPT trial, showed that SUs and DPP-4 inhibitors showed the shortest durability which ranged between 3.3 to 4.4 years while the sodium glucose transporters- 2 and thiazolinediones class of medications exhibited a projected time to A1c neutrality from 6-8 years. Thus the duration of treatment with SUs is an important factor which should be known at the time of making the treatment decision [25].

Whether the use of SUs is associated with higher cardiovascular risk or not, is one of the most controversial issues concerning that particular class of oral antidiabetic agents. The debate began in the 1970s, when the University Group Diabetes Program reported an increased risk for cardiovascular disease and mortality with the use of a first-generation SU, tolbutamide [26]. Since then, mostly observational studies have associated SUs with higher risk compared to the rest oral antidiabetic medication when compared as monotherapy or in combination with metformin. Quite recently, the TOSCAT Trial points out that SUs might be associated with an increased heart failure risk [27].

The issue of cardiovascular risk associated with SUs has been supported by the description of a specific mechanism. As mentioned, SUs bind to potassium ATP-dependent channels. Apart from the pancreatic $\beta$-cells, these channels are also located in several other tissues, including smooth and skeletal muscle and neurons. Specifically in the myocardium, potassium channels participate in a very interesting mechanism called "ischemic preconditioning". It is essentially a process of restrained, temporary and non-fatal ischemia that protects the myocardium against lethal ischemia by making it more resilient. By binding to potassium channels in the myocardium, SUs induce closure of the channels and subsequently obstruct ischemic preconditioning. This feature of SUs could potentially increase cardiovascular risk in patients with diabetes [28-30]. However, existing randomized clinical trials have failed to clarify the issue and really assess the long term safety outcomes [31]. Studies like ADVANCE and ACCORD did not report a rise in cardiovascular mortality in SU-treated patients and recent metaanalyses continue to give opposing results [32].

As a repercussion from these adverse outcomes, authors express different opinions. Some are convinced that the existing data are enough to raise serious concerns about the safety of SUs [18], while others continue to believe that there is no clear evidence for the association of SUs with cardiovascular disease and mortality [6]. Even the American Diabetes Association guidelines that were published in 2019 appear to be conflicting. On the one side, SUs are characterized as "neutral" in cardiovascular risk. However, there is a special FDA warning that points out the higher risk of cardiovascular mortality based on studies on an older first-generation SU, tolbutamide. According to ADA, in patients with DM2 and atherosclerotic cardiovascular disease, the agent that should be added to metformin should have proven cardiovascular protection. For the time being, such agents are specific sodium glucose transporters 2 (SGLT2) inhibitors (empagliflozin and canagliflozin), as well as one GLP-1 receptor agonist (liraglutide) [33].

In conclusion, SUs still constitute a valid choice in patients with DM2. They are inexpensive and have a great initial efficacy in glycemic control. However, several adverse effects have sparked controversy and risen some serious questions concerning their long-term safety. The hypoglycemic episodes and the weight gain, even if they are mild, worsen glycemic control and disrupt the patients' quality of life. The progressive pancreatic $\beta$-cell failure accelerates the need for further antidiabetic agents and, eventually, insulin. Concerning the cardiovascular safety, the existing evidence are worrisome and more studies are needed in order for the issue to be settled. SUs still can be prescribed in DM2 patients that are inadequately controlled with metformin as monotherapy or exhibit side effects or contraindications with other antidiabetic medications. Preferentially, SUs should be prescribed in young age patients or middle aged patients with no comorbidities which could be adversely affected by SUs treatment and for a short time. As long as older patients are concerned, clinicians should contemplate all aspects and select short acting SUs with lower risk for hypoglycemic episodes. All in all, given the fact that there are newer antidiabetic agents with comparable efficacy and a safer profile, it is reasonable to select a different treatment other than SUs, unless there are major cost or health issues.

\section{References}

1. White JR Jr (2014) A brief history of the development of diabetes medications. Diabetes Spectr 27: 82-86. [Crossref]

2. Quianzon CC, Cheikh IE (2012) History of current non-insulin medications for diabetes mellitus. J Community Hosp Intern Med Perspect 2. [Crossref]

3. Turner LW, Nartey D, Stafford RS, Singh S, Alexander GC (2014) Ambulatory treatment of type 2 diabetes in the U.S., 1997-2012. Diabetes Care 37: 985-992. [Crossref]

4. Seino S, Sugawara K, Yokoi N, Takahashi H (2017) B-Cell signalling and insulin secretagogues: A path for improved diabetes therapy. Diabetes Obes Metab 1: 22-29. [Crossref]

5. Sherifali D, Nerenberg K, Pullenayegum E, Cheng J, Gerstein H (2010) The Effect of oral antidiabetic agents on A1C Levels: A systematic review and meta-analysis. Diabetes Care 33: 1859-1864. [Crossref]

6. Abrahamson M (2014) Should sulfonylureas remain an acceptable first-line add-on to metformin therapy in patients with type 2 diabetes? Yes, they continue to serve us well! Diabetes Care 38: 166-169. [Crossref]

7. Morgan C, Poole C, Evans M, Barnett A, Jenkins-Jones S (2012) What next after metformin? A retrospective evaluation of the outcome of second-line, glucose-lowering therapies in people with type 2 diabetes. J Clin Endocrinol Metab 97: 4605-4612. [Crossref] 
8. UK Prospective Diabetes Study (UKPDS) Group (1998) Intensive blood-glucose control with sulphonylureas or insulin compared with conventional treatment and risk of complications in patients with type 2 diabetes (UKPDS 33). Lancet 352:837-853.

9. Patel A, MacMahon S, Chalmers J, et al.; ADVANCE Collaborative Group (2008) Intensive blood glucose control and vascular outcomes in patients with type 2 diabetes. N Engl J Med 358:2560-2572

10. Irvine H, Male S, Robertson J (2019) Reduced intracerebral hemorrhage and perihematomal edema volumes in diabetics on sulfonylureas. Stroke 50: 995-998. [Crossref]

11. Klarenbach S, Cameron C, Singh S, Ur E (2011) Cost-effectiveness of second-line antihyperglycemic therapy in patients with type 2 diabetes mellitus inadequately controlled on metformin. Can Med Assoc Jour 183: E1213-E1220.

12. Hong D, Si L, Jiang M, Shao H, Ming W, et al. (2019) Cost effectiveness of sodiumglucose cotransporter-2 (SGLT2) inhibitors, glucagon-like peptide-1 (GLP-1) receptor agonists, and dipeptidyl peptidase-4 (DPP-4) Inhibitors: A systematic review. Pharmaco Economics 11. [Crossref]

13. Henquin JC (2017) Misunderstandings and controversies about the insulin-secreting properties of antidiabetic sulfonylureas. Biochimie 143: 3-9. [Crossref]

14. Tahrani A, Barnett A, Bailey C (2016) Pharmacology and therapeutic implications of current drugs for type 2 diabetes mellitus. Nat rev endocrinol 12: 566-592.

15. Pagkalos E, Thanopoulou A, Sampanis C, Bousboulas S, Melidonis A, et al. (2017) The Real-Life Effectiveness and Care Patterns of Type 2 Diabetes Management in Greece. Exp Clin Endocrinol Diab 126: 53-60. [Crossref]

16. Del Prato S, Pulizzi N (2006) The place of sulfonylureas in the therapy for type 2 diabetes mellitus. Metabolism 55: S20-27. [Crossref]

17. Longo M, Bellastella G, Maiorino MI, Meier JJ, Esposito K, et al. (2019) Diabetes and aging: from treatment goals to pharmacologic therapy. Front Endocrinol (Lausanne) 10: 45. [Crossref]

18. Genuth S (2014) Should sulfonylureas remain an acceptable first-line add-on to metformin therapy in patients with type 2 diabetes? No, It's time to move on! Diabetes care 38: 170-175.

19. Bennett WL, Maruthur NM, Singh S, Segal JB, Wilson LM, et al. (2011) Comparative effectiveness and safety of medications for type 2 diabetes: an update including new drugs and 2-drug combinations. Ann Intern Med 154: 602-613. [Crossref]

20. Davies M, D’Alessio D, Fradkin J, Kernan W, Mathieu C, et al. (2018) Management of hyperglycaemia in type 2 diabetes, 2018. A consensus report by the American diabetes association (ADA) and the European association for the study of diabetes (EASD). Diabetologia 41: 2669-2701. [Crossref]
21. Dunkley A, Fitzpatrick C, Gray L, Waheed G, Heller S, et al. (2019) Incidence and severity of hypoglycaemia in type 2 diabetes by treatment regimen: a UK multi-site 12-month prospective observational study. Diab Obes Metabol 6. [Crossref]

22. Farahani P (2017) Non-Severe hypoglycemia risk difference between sulfonylurea and sodium-glucose cotransporter-2 inhibitors (Sglt2-I) as an add-on to metformin in randomized controlled trials. J Popul Therap Clin Pharmacol 24.

23. Farah D, Leme G, Eliaschewitz F, Fonseca M (2019) A safety and tolerability profile comparison between dipeptidyl peptidase- 4 inhibitors and sulfonylureas in diabetic patients: A systematic review and meta-analysis. Diab Res Clin Pract 149: 47-63. [Crossref]

24. Kahn SE, Haffner SM, Heise MA, Herman WH, Holman RR, et al. (2006) Glycemic durability of rosiglitazone, metformin, or glyburide monotherapy. $N$ Engl J Med 355: 2427-2443. [Crossref]

25. Cherukuri L, Smith MS, Tayek JA (2018) The durability of oral diabetic medications: Time to A1c baseline and a review of common oral medications used by the primary care provider. Endocrinol Diabetes Metab J 2. [Crossref]

26. Meinert C, Knatterud G, Prout T, Klimt C (1970) A study of the effects of hypoglycemic agents on vascular complications in patients with adult-onset diabetes. II. Mortality results. Diabetes 19: 789-830. [Crossref]

27. Packer M (2018) Are physicians neglecting the risk of heart failure in diabetic patients who are receiving sulfonylureas? Lessons from the TOSCA.IT trial. Eur J Heart Fail 20: 49-51. [Crossref]

28. Riddle M (2003) Sulfonylureas differ in effects on ischemic preconditioning - Is it time to retire glyburide? J Clin Endocrinol Metabol 88: 528-530. [Crossref]

29. Lazdunski M (1996) Ion channel effects of antidiabetic sulfonylureas. Horm Metab Res 28: 488-495. [Crossref]

30. Stokfisz K, Ledakowicz-Polak A, Zagorski M, Zielinska M (2017) Ischaemic preconditioning - current knowledge and potential future applications after 30 years of experience. Adv Med Sci 62: 307-316. [Crossref]

31. Powell W, Christiansen C, Miller D (2018) Meta-Analysis of sulfonylurea therapy on long-term risk of mortality and cardiovascular events compared to other oral glucoselowering treatments. Diab Ther 9: 1431-1440. [Crossref]

32. Ferrannini E, DeFronzo RA (2015) Impact of glucose-lowering drugs on cardiovascular disease in type 2 diabetes. Eur Heart J 36: 2288-2296. [Crossref]

33. American Diabetes Association (2019) 9. Pharmacologic approaches to glycemic treatment: Standards of medical care in diabetes-2019. Diabetes Care 42: S90-S102. [Crossref]

Copyright: (C2019 Manta A. This is an open-access article distributed under the terms of the Creative Commons Attribution License, which permits unrestricted use, distribution, and reproduction in any medium, provided the original author and source are credited. 